\title{
Marine cities: a vision for a future China
}

\author{
S.-M. Lu \\ Department of Architecture, Shanghai Jiao Tong University, China
}

\begin{abstract}
Through reviewing theories and models of aquapolis and analyzing the advantages and feasibilities of creating marine cities, the author takes a fresh look at the vision of marine cities. Using text and images, he elaborates on several cases and their strategic planning of marine settlements along the coastline as well as inland for a China of the future. With an optimistic view, he argues that living on the water will not only provide one of the considered future lifestyles in China, especially in Shanghai, but will also contribute towards a new frontier for the world, as a place for those who wish to experiment with new building technologies, a new marine landscape, and new urbanism.
\end{abstract}

Keywords: marine city, future China, urban planning, ecologic, local context.

\section{Introduction}

Due to the pressure of environment, population and natural resources, it is necessary for human beings to explore new regions to live in. There are three kinds of places that could be chosen: in the sky, underground and on the sea. The last of these seems the easier, more active and attractive choice. Ideas such as an aquapolis, a sea city or marine city were born in city models as well as from the literature of films. Architects who are dedicated to establishing different theories of a city on the water have built inspiring scale models, for example, Kenzo Tange's Tokyo Bay Project (丹下健三, 1960), Kiyonori Kikutake's Marine City Project (菊竹清训, 1958), Arata Isozaki's Haishi Project (矶崎新, 2006), Constant Nieuwenhuys's New Babylon Photomontage (1971), CJ Lim's Virtually Venice (2004), Jean Nouvel's Remodelling of the Central Port Area of Vigo (2007), Zahard Hardid's Digital London (2008), Vincent Callebaut's Archibiotic (2008), Palo Alto's Sea-stead Structure (2010) and so on [1]. 
The topic of marine city is also one of the interesting themes of World Expo. For example, Expo Naples 1954 (Italy), Expo Okinawa 1975 (Japan), Expo Zaragoza 2008 (Spain). In the World Expo 2010 Shanghai, Urban Dream Pavilions, the Singapore Pavilion and Korea Business Pavilion also elaborated on the topic of future cities on the water: mega-buildings were designed; floating on the water and equipped with all kinds of modern facilities. Furthermore, human beings would play in the ecological and safe environment of the ocean, swimming like fish with artificial gills, and so on.

Actually, the new territories (e.g., Dubai) are seen as expanses to be built, first with romantic visions, then with scientific images, and later with vistas designed to entice economic developers and dwellers, which also show the attempts of designers to project their imaginative visions on a region where the future might happen as planned.

Views from history, geography and the natural environment show the possibility of the marine mode in China. Besides, technologies of engineering (i.e., bridges, tunnels, artificial islands and ports, water, marine farming and new energy technology) make it more feasible in the future. On the other hand, China needs to renew the mode of marine city in the future due to its high speed development and its accompanying requirements, such as new requirements of dwellings, new competition of economy and technology, and new vision of human inspiration. The marine city has the advantage of being a water-based environment, so it could enjoy more ecological and poetic living, waterbased leisure, and marine economy. What's more, the attention of the government has been focused on the 'ecopolis' and its revolutionary projects, especially from the 2008 Olympic Games and the 2010 World Expo.

Nevertheless, we need to create new temporal space and new cities for the future. What will China cities look like in 2050? With this in mind, the following cases may help to shape the ideas of the future marine city [2].

\section{Marine city in China 2050}

Generally, a marine city (also called a marine community, city on water and aquapolis) is a structure which means permanent occupation on the ocean. It could integrate residents, parks and transportation with open spaces. The vision for a marine city is of a city whose community is connected to the water. Through a series of water-themed programs and events and relevant activities including entertainment, cultural activities, education, employment and business development opportunities, the city is linked to the water mentally. In this way, whether the city is located along the coastline or inland, it could be called a marine city. More than a regional geography, the future city on the sea shows new visions of the place for China.

In the following cases, the colonization of water for permanent dwellings generates new modes of community which expand the horizons in the oceans around China. A marine city could host 50,000-100,000 people in a single community, which looks like an eco-island, a green boat or a landscape platform without a car. Housing, offices, laboratories, shops and recreation areas will 
share spaces with solar panels, wind turbines, marine resources, tidal power stations and so on. Marine parks, water channels, lakes, marine farming and landscape are integrated in the marine village building with an ecological and safe environment. It will be a sustainable, carbon neutral, zero waste community of the world.

The planning principles could be considered. Firstly, the location of large new residential areas could be near employment points along the coastline, such as Yangshan Gang in Shanghai, Bay near Old Town Haining, Yangtze River along Waterfront City Maanshan etc. Large-scale public utilities such as bridges and tunnels should be built at the first stage, and the convenience of accessibility should be carefully defined. Secondly, the construction of a walled platform and arena should be secure and safe, protecting the town from waves, wind and noise pollution. Equipment such as the power station, gas works, water treatment plant and so on should be integrated with it. Next, the formulation of the sea community can recall people of the image of the old town and local context. The functions of community should be mixed, there being designs for housing, offices, laboratories, sea farming and so on. Then, ecologic and information technologies would be practiced: energetic autonomy, vegetable roofs, intelligent buildings, wind machines, public transportation with new energy, recycling of the waste and the used waters, highly advanced building materials or local material, digital streets, intelligence spaces, interactive objects and facilities, etc. The creation of the waterside parks for the improvement of recreation amenities and decision-making of water-based events will be considered. Besides, the marine community not only hosts inhabitable spaces for future Chinese people but also natural biotopes suitable to the local climate by inviting the biodiversity to develop its habitation which would be surrounded by amphibians, mammals, birds, insects, flowers, grass, shrubs and trees.

This is a new built ecosystem with Chinese traditional thoughts, which always refuse to separate nature from human beings $[3,4]$. The portrait of a marine city will be described in four layers:

(1) Landscape urbanism. Traditional Chinese painting and gardening normally deliver the key idea that human settlements cannot be isolated from the mountain, waterscape or landscape; whether natural or man-made. Mini-gardens, in particular, represent the landscape of the miniature world in Jiangnan Gardens. So the marine city would be built with landscape, or bio-landscape or biologic intelligence. The Old Euclidean structure is merged with Boolean connections and mesh smooth modification into a new layered and interconnected form of cities. In this perspective, all the buildings and the infrastructure are considered as abstractions of the geographies and hybrid ecosystem. The landscape urbanism mixes landscape technology and biodiversity with a maximum use of water and vegetable, where people can touch nature whenever and wherever they walk [5].

(2) Sensitive urbanism. As a Chinese philosopher says, the body and spirit would not exist without each other, and human being and his/her habitation are usually integrated with each other. Basically, equipped with an invisible numeric 
infrastructure, the citizen can work, communicate and shop freely and conveniently in the city. Further, information and communication technology enable people to manipulate the information by software and hardware so as to generate the complex but intelligent buildings and interactive streets, which can translate the parameters of vision, hearing, smell, taste, and touch into the spatial sensations felt by the inside residents and outside visitors.

(3) Ecologic urbanism. The function model of a marine city is based on the water, tidal thermo-station, tidal power station, submarine propellers, biomass, hydraulic industry, marine farming and fishing. It will make full use of organic materials, renewable materials, waste building materials and biotechnological material to configure the identity of the marine city. Instead of automobile transportation, continuous pedestrian or bicycle promenades link open spaces, swimming pools and seafronts with piers. Citizens can enjoy the biodiversity of the matrix, patch and corridors provided $[6,7]$.

(4) Situationist urbanism. New techniques markedly alter, more or less, all aspects of everyday life, although many of them are unrelated to the requirements of ordinary people and local contexts. Therefore, the cultural identity should be projected onto the model of a marine city via everyday objects and life. Generally speaking, three dimensions of habitat spaces (i.e. local climate, psycho-geographic and social) could nurture the context of the new world through the representation of colors, signs, materials and fabrics [8].

Under these circumstances, several different models of marine cities are proposed for different cities.

\subsection{Marine Shanghai}

Like New York, London, Paris, and Tokyo, Shanghai has to find a new place to develop if we are to survive in 2050.

The City of Shanghai, the largest city in China and one of the largest in the world, sits on the south edge of the mouth of the Yangtze River and is situated along the Huangpu River. The Huangpu River divides the city into east and west, Pudong and Puxi. Puxi is the old part of the city with the west side of the Huangpu River fronted with the famous Bund, while Pudong is a new part of Shanghai, with the oriental Pearl TV Tower sitting in front of new high-rise CBD.

Shanghai originated as a small fishing village about 700 years ago during the Tang Dynasty. Its rise is largely due to its role as a treaty port since the 1840 s. After nearly one hundred years' development, the city sprawls for miles from downtown areas to Baoshan district and Minhang district and gradually forming a linear mode along the Huangpu River $[9,10]$. However, it is necessary that this spatial mode which the city shaped up during its 30 year development should be changed: from a mono-centric pattern to a multi-centric network pattern; and from an inland mode to a marine one.

One feasible strategy is to integrate the waterscape with greenery to develop open waterfront spaces for urban living use. Two steps need to be taken to 
realize this aim. Firstly, the Huangpu River and its inland networks need to be reclaimed with conservation. Secondly, it is essential to develop waterfront spaces and marine communities along the coastline, i.e., the Chongming Island and new Pudong area, starting from Dongtan, Wai Gao Qiao, Jing Qiao, San Jia Gang, Pudong Airport, Lin Gang Newtown, Yangshan Gang, Fengxian Beach to Jingshan Port along Hangzhou Bay. Actually, one fact that should not be neglected is that the city enjoys a 172 kilometer long coastline and a 532 square kilometer water-bodies inland, making up about 9 per cent of the total area.

Owing to the relationship between the city and water and the charm/ enchantment of the city, several figures contribute great ideas of marine modes for Shanghai at different stages. For example, Mr. Sun Zhongshan proposed planning an oriental grant port for Shanghai in 1920. At the turn of this century, Yona Friedman conceived a Bridge Town of Utopian Shanghai over the Huangpu River (fig. 1). In addition, a floating environmental-friendly city is designed for World Expo 2010 Shanghai by a Dutch Architect, in which a 3D cinema, a Bar, a shopping mall and a restaurant could be built (fig. 2) [11]. It shows diverse eco-pavilions floating on the water connected with network pedestrian systems, which integrate transportation, exhibition, leisure and parking with open spaces on the Huangpu River.

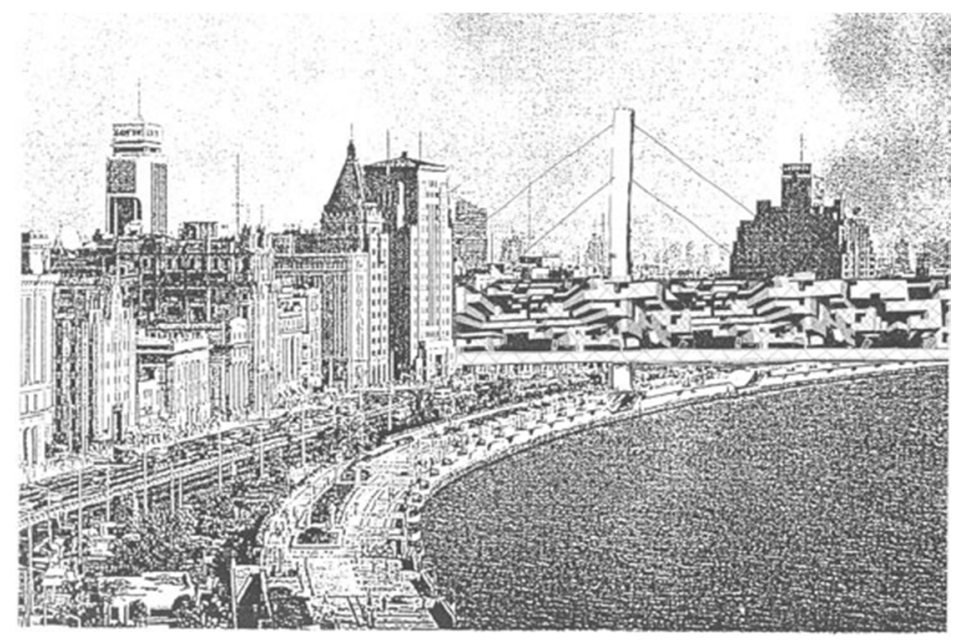

Figure 1: Bridge town of Utopian Shanghai (http://www.expo2010.cn/).

Other models and pictures: Aquatic Chip could catapult citizens into the future of Shanghai, which allows for new solutions, adaptable to any conceivable location, such as near Yangshan Gang, near Pudong Airport and so on.

Aquatic Chip has been proposed for the Shanghai government to connect the existing urban landscape with the new cultural facilities. Multifunctional buildings are located on the water and organized as a chip. Two dams exist there as the border of the water community. The landscape axis in an east and west 


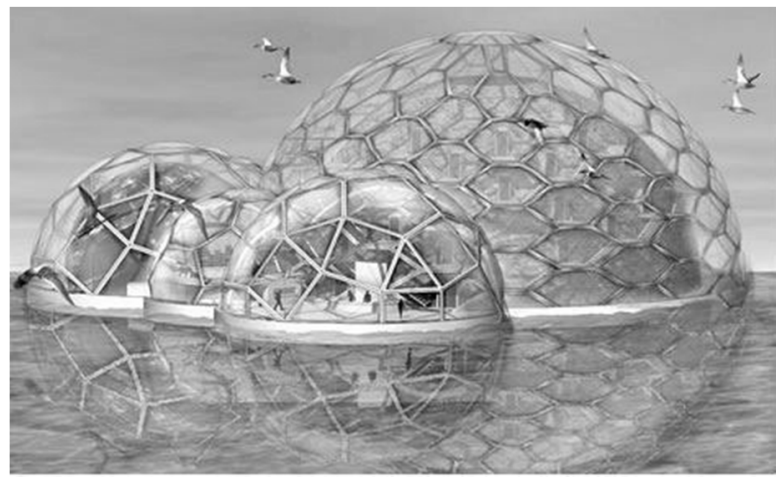

Figure 2: A proposal model for 2010 EXPO Shanghai (http://www.expo2010.cn/).

direction is emphasized. Paths reaching each entrance and sighting lines intersect at the central zone (fig. 3).

"The integrated circuit" is the main meeting place, where exhibition buildings, office buildings and apartment hotels are floating there. The position of the main convention and exhibition hall is similar to that of the CPU chip in an integrated circuit; those exhibition halls and museum, such as the screen culture exhibition hall, performing arts exhibition hall, action arts exhibition hall, image arts exhibition hall, music and opera arts exhibition hall, are located at the position of those card slots in an integrated circuit. They perform well, which are very much like those cards assembled in the integrated circuit. Additionally, they match along with and interact with the five outdoor gardens, just like the cards communicate with the peripheral equipment. Continuous open spaces are created between open-air swimming pools, marinas and pedestrian or bicycle promenades along ecologic corridors.

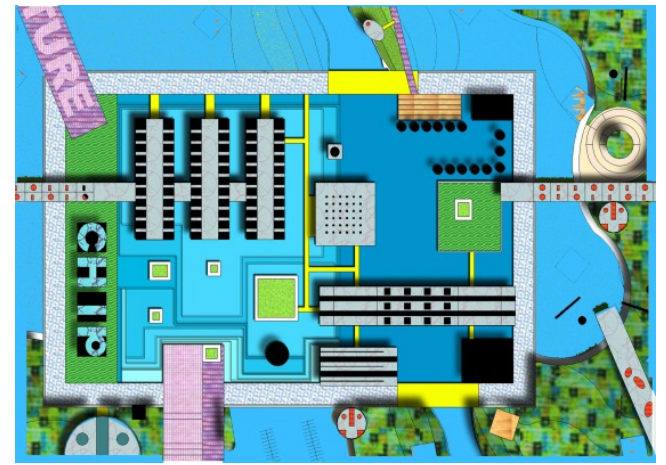

Figure 3: Aquatic Chip proposal plan. 
Apart from those exhibition halls in the central zone there are: a performing stage, fair ground, sculpture square, bars, on water club, etc.

The whole master plan (fig. 3) shows the vision of landscape urbanism.

\subsection{Water city with color (Honggutan, Nanchang, 2003)}

Each strand waterfront city in the world is looking for its unique way to enhance its marine identities. By doing so, it is not only for the development of the city and its tourism, but is also for the good of its inhabitants. This trend could be easily found in the master plan of some influential strand water city in China. The project of a water city with color shows this ambition. In the master plan, new technologies and geometries are applied. With non-linear models, we felt after a solution to improve its environment quality of the water city. Furthermore, we sought at a higher level to give full play to the unique features of Honggutan, the new district of Nanchang city, which is different from other strand water cities (fig. 4).

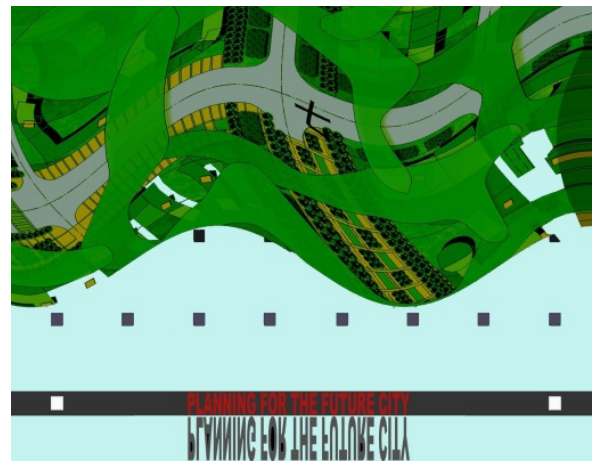

Figure 4: Water city with colour.

In order to show a magnificent master plan of a water city, which is unique and full of energy, high technology is used to design its landscape in this conceptual phase, as follows:

Green strategies: green corridors, roof gardens, green platforms, hanging gardens, aerial gardens and the greenway etc. Combining the aerial gardens, roof gardens, green forms, green corridors, we would like to stroll in the green world, and feel breeze, fresh air and fitting humidity everywhere. Biotechnologies would also be considered during the construction of buildings.

Yellow strategies: the utilitization of solar energy. We designed sign posts for advertisements, the solar collection with infrastructure construction. The solar collection is integrated with equipment rooms and walls in the gardens or the pavilions. 
Red strategies: public open spaces. The central gardens, waterfront gardens and wharfs act actively in the open spaces at the waterfront.

The goals of this design are summarized: first, to create entirely new and multi-dimensional hanging gardens for the new era; second, to create a marvelous and ecological digital city landscape facing the future; finally, to create a unique identifiable heroic city landscape. The concept of sensitive and ecologic urbanism is well defined.

\subsection{Floating island with stories}

The idea of a floating island with stories has been proposed for the town of Wuyishan, Fujian province. Located at a shoal along the brook, 13 floating islands with natural shapes and topographies are proposed within this master plan and have their different stories which are related with the histories of the town to recall the spirit of the place (fig. 5). Meanwhile, each island is defined with different functions: hotel, museum, villa, etc., which are also given with different legends based on different historical tales. Furthermore, nice bridges, titled with traditional literary names, are linking each other. These buildings and infrastructure are made up of local materials (i.e. woods and couch grass) and bionic styles (such as mushrooms and lotus).

That is to say, these represented identical islands, buildings and bridges not only remind residents where they live and travel but also evoke their ancestors' lifestyle and their ritual activities. The case of the watery village tries to express the concept of situationist urbanism.

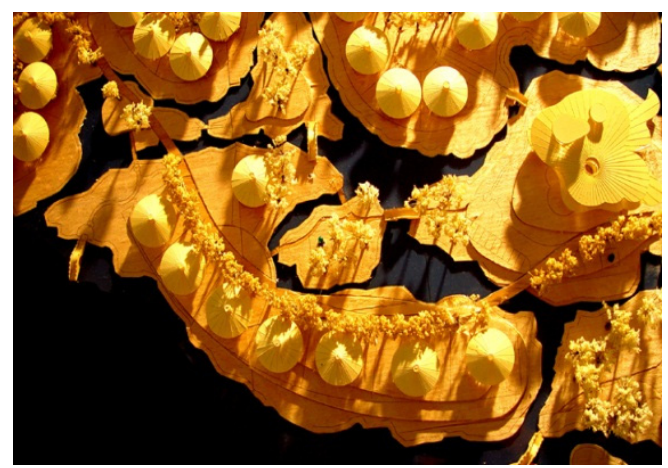

Figure 5: Floating Island (Wuyishan, Fujian, 2003).

\subsection{Living on the water (Maanshan, Anhui, 2004)}

The model of marine Maanshan is planned according to the axis of the main streets and a bank is arranged around the edge which represents a first obstacle protecting the center from waves and bad weather. Waterfront ecological space is supplied for citizens, meanwhile the look of an urban waterfront landscape is also considered. In total, the green land accounts for no more than 60 per cent, 
among which the land for open space is no less than 30 per cent; the land for construction is controlled below 40 per cent. The main functions are as follows: leisure, entertainment, living, work and meeting etc. The north mountain is defined to form the "wall" to prevent noise, pollution and wind. Along the green zone along the waterfront, we designed series gardens, which act as the function of the reservoir as well as represent the historic, local stories of Maanshan to extend the culture and landscape of Caishiji (fig. 6). The island is connected to the mainland with greenbelts and highway. Meanwhile, we made full use of sunshine, breeze and water as renewable energy for the marine town based on the theory of ecologic urbanism.

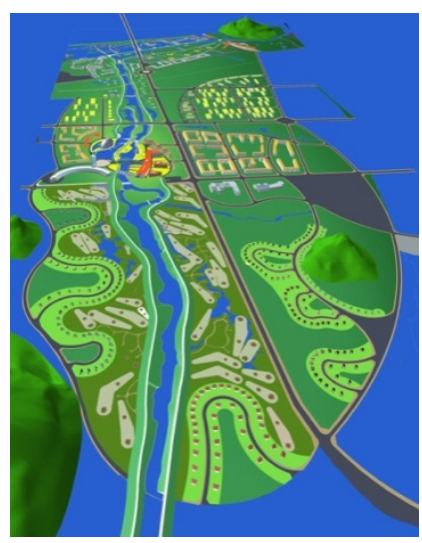

Figure 6: Living on the water (Maanshan).

\section{Conclusion}

To some extent, these proposal models represent the ideas of marine cities and show different visions of future cities in China. Although each case enjoys different geographical conditions and local culture, every case shows the interrelation between future marine cities, water and the neighboring cities according to natural, sensitive, ecological and cultural layers. Firstly, the water, green and topography should be organically merged into the marine plots based on landscape and ecology. Secondly, the local cultural context and social activities should be considered to project onto these watery spaces. Next, links are needed to combine the marine communities with the main cities nearby, which these facilities can work together and host colorful life.

However, lots of questions arise, such as how to overlap these four layers (i.e., landscape, sensitive, ecological and situationist), what about the economic costs or environment impact and so on. Nevertheless, living on water will not only provide one of considered future lifestyles in China, but also contribute a new frontier for the world for those who wish to experiment with new building technologies, new marine landscape, and new city. 


\section{Acknowledgements}

This research is supported by Natural Science Foundation of China (51278292, 41471120) and Social Science Foundation of China (14ZDB139).

\section{References}

[1] Vincent Callebaut, The Future City. Maksimym [J], (09), pp. 106-107, 2009.

[2] Eric D. Olmanson, The Future City on the Inland Sea: A History of Imaginative Geographies of Lake Superior. Ohio University Press: Athens, 2010.

[3] Chris Goodall, How to Live a Low-Carbon Life: The Individuals Guide to Stopping Climate Change [M]. Earthscan, 2007.

[4] Valerie Lee \& Beryl McDowall, Living Afloat [M]. Residential Boat Owners' Association: Leics., pp. 5-6, 2007.

[5] Shaoming Lu, Urban Cluster Space Framed by Landscape. Architectural Journal (Chinese), (06), pp. 8-11, 2007.

[6] Douglas Farr. Sustainable Urbanism: Urban Design with Nature [M]. John Wiley \& Sons Inc., 2007.

[7] Mumovic D., Santamouris M., A Handook of Sustainable Building Design and Engineering - An Integrated Approach to Energy, Health and Operational Performance of Building. [M] Earthscan/James \& James Publishers: London, 2009.

[8] Simon Sadler, The Situationist City, MIT: Mass., 1999.

[9] Bo-ke Mao, The History of Shanghai Port [M]. The People's Transportation Press: Beijing, 1986.

[10] Congzhou Chen, Ming Zhang. The History of Modern Architecture in Shanghai. Shanghai: Shanghai San-Lian Bookshop. pp. 20-21, 1988.

[11] World Expo Shanghai 2010, http://www.expo2010.cn/ 